\title{
Collaboration and Evolution of E-Commerce and Express Delivery Industry Supply Chain
}

\author{
Ying Xu, ${ }^{1}$ Xuemei Zhang, ${ }^{1,2}$ Jian Cao, ${ }^{2,3}$ Ya Chen, ${ }^{2,4}$ and Xuhong Ye ${ }^{2}$ \\ ${ }^{1}$ College of Economic Commerce, Ningbo Dahongying University, Ningbo 315175, China \\ ${ }^{2}$ College of Economics \& Management, Zhejiang University of Technology, Hangzhou 310023, China \\ ${ }^{3}$ Department of Civil \& Environmental Engineering, The University of Iowa, Iowa City, IA 52242, USA \\ ${ }^{4}$ Zhejiang Technical Institute of Economics, Hangzhou 310018, China
}

Correspondence should be addressed to Jian Cao; jcao@zjut.edu.cn

Received 5 June 2016; Accepted 15 November 2016

Academic Editor: Paolo Renna

Copyright (c) 2016 Ying Xu et al. This is an open access article distributed under the Creative Commons Attribution License, which permits unrestricted use, distribution, and reproduction in any medium, provided the original work is properly cited.

\begin{abstract}
Considering the contradictions between the electronic commerce (e-commerce) and its matching express delivery service, this paper investigates a supply chain regarding e-commerce and express delivery industry, in which collaborative operations of enterprises are discussed. The profitability and collaboration capability acting as order parameters and the rest of the influential resources including logistics, fund, information, and commodity are selected with their interrelations being examined based on servo theory of synergetics. Besides, evolutionary model of the e-commerce and express delivery industry is established and analyzed according to self-organization method of system dynamic theory to illustrate order parameters' role in system evolution, and numerical analyses emerged to intuitively demonstrate the solutions. We conclude the work along with its results of significant references for investigating resource integrations by combining the two closely related businesses in an entire cooperative supply chain and providing guidelines for e-commerce and express delivery enterprises and industries in effective collaboration and system evolution.
\end{abstract}

\section{Introduction}

In company with the acceleration of economic globalization and regional integration, electronic commerce (e-commerce) industry has been thriving during the past few decades. Developed countries, Europe in particular, have enjoyed e-commerce booming with a market size of $\$ 426$ billion, accounting for $35 \%$ of e-commerce market share globally in 2012 , followed by $33.1 \%$ with a number of $\$ 389$ billion in North America market [1]. Asia-Pacific has witnessed persistent development of e-commerce at an unprecedented rapid speed since 2013 with an average growth rate of $23 \%$, while China and Indonesia stand out as the two fastest-increased e-commerce regions that hold a year-on-year growth of $65 \%$ and $71 \%$, respectively [2]. Specifically, as middle class in China has become more web-savvy in recent years, online business in the country, driven by technological innovation as well, remains prosperous.
To e-commerce industry, logistics service is of vital significance for regular operations as well as further innovations and breakthroughs to better satisfy customers. While ecommerce industry has progressed and improved constantly, contradictions have arisen between e-commerce and its matching express delivery service that needs to be better regulated and standard simultaneously. Statistics and surveys have proved, however, that the express system in China has got low flow rate of efficiency, limited management area, and poor corresponsive ability for market changes, which have inevitably inhibited further development of ecommerce industry [3]. As a response to this new challenge, coordination and cooperation between e-commerce and express delivery enterprises should be attained for win-win development. In fact, the rapid expansion of e-commerce has indeed brought about dramatic opportunities for express industry which in turn determines the quality and efficiency of e-commerce undertakings. Therefore, study of synergistic 
model along with its evolutionary process of the so-called "ecommerce and express industry supply chain" in this paper comes into notice.

In this paper, a supply chain considering e-commerce and express delivery enterprises is taken into account. Servo theory of synergetics and self-organization method of system dynamics theory are employed to investigate the intraand interrelations among influential elements impacting the collaborative undertakings of e-commerce and express delivery industry across the supply chain. Besides, relevant numerical analyses emerged to corroborate and supplement the theoretical exploration.

\section{Literature Review}

To our knowledge, existing literatures mostly concern practical issues on supply chain collaborative management such as the significance of synergy among supply chain members $[4,5]$, the advantage of resource integration and interaction of channel members [6-8], strategies or incentives for successful cooperation and coordination in the system [9-12], and mode selections and practices of joint operations [13-15]. Among these, considerable attention has been paid to collaborative supply chain of single industry, while relevant researches conveying two or more industries are few and channel cooperation under e-commerce environment has not been mentioned yet.

Since the conceptually prospective ideas on supply chain collaboration under e-commerce background have been proposed, relating studies are believed to be highly significant in promoting management innovation of logistics systems for further breakthroughs of e-commerce development [1619]. Channel adaption and member behaviors of a supply chain consisting of the manufacturer and retailer under ecommerce environment are considered in [20]. Reference [21] figures out that win-win development of e-commerce and private courier is becoming tendency with corresponding recommendations provided. Reference [22] declares that supply chain management of circulation fruits and vegetables could be better implemented with the e-commerce service platform equipped with advanced IT applications. B2B (Business-to-Business) e-commerce technology adoption of organizations within the grocery industry supply chain is examined in [23]. Reference [24] analyzes the integration capabilities of $\mathrm{B} 2 \mathrm{~B}$ e-commerce from the perspective of capital and market operations and production and demand uncertainty in the supply chain as an influential factor. Reference [25] explores the role of e-commerce environmental management in improving support abilities of collaborative operations through confirmatory factor analysis. Reference [26] investigates the relations between supply chain management and e-commerce operation in automobile industry to illustrate the feasibility and necessity of managing the industrial chain taking advantage of e-commerce superiority. In sum, there are two prevailing topics of supply chain collaboration under e-commerce platform: (i) supply chain management innovations in the face of challenges and opportunities brought by the booming e-commerce industry and (ii) collaborative e-commerce supply chain management to attain a win-win status. Both research orientations, however, tend to overlook a potentially crucial role of influential factors within the channel that virtually should not be ignored in the collaboration and cooperation across the entire supply chain. In fact, profitability and interoperability along with the circulation of commodity, fund, information, and logistics are of vital importance in supply chain operations. In this paper, we further investigate supply chain coordination along with its evolutionary process of e-commerce and express delivery industry considering horizontal collaborations among various resource elements that combine the two closely related businesses in an entire cooperative supply chain.

As is known to all that the circulation of commodity, logistics, information, and fund is the basis and premise for e-commerce initiatives, researches on their connotations and interrelations have been prolific [27-29]. Besides, it is insufficient to merely cooperate one resource element between two nodes vertically for supply chain collaboration, horizontal collaboration that various factors are jointly considered should be emphasized even more. That is to say, the entire synergy could be attained only if the cooperative interactions are fulfilled among all influences both longitudinally and transversely [30]. In recent years, naturally, an increasing number of scholars examine issues of coordinative resource elements on supply chain operations. For example, [31] figures out that product and capital turnover reflected on information transmission constitute the basis for cooperative mode of agriculture product circulation. Reference [32] presents a brand-new $5 \mathrm{~F}$ research model that introduces business flow and work flow as additional elements, compared with traditional physical, fund, and information flow, for resource integration and consolidation. Reference [33] addresses a collaborative supply chain system in which the flows of capital, goods, and information are optimized to enhance service innovation capabilities.

Previous approaches applied in supply chain collaboration are diverse, while mathematical models involving the confirmatory factor analysis, structural model formulation, mixed integer programming, and game theory methods [3436] are proved to be applicable under specific assumptions and limitations. Meanwhile, adoptions of servo theory of synergetic and system dynamics methods, which belong to mechanical discipline initially, have taken place dramatically in supply chain collaboration [37-39]. Servo theory illustrates that the resource and operation elements should work externally and internally so that a well-regulated system could be accomplished [40]. Additionally, though the order parameters occupy a relatively smaller rate compared with a diversity of the rest of the elements in the supply chain, they make the entire system stable in its transition from disordered to ordered condition and the progress of low-ordered state converting to a high-ordered one [41-43]. The principle of self-organization of system dynamic [44-49] is employed in our work to present interrelations between order parameters and other resource elements through differential equations formulation and calculation.

As such, our objective is to take a sound look at the interactions and connectedness among all influential factors of ecommerce and express delivery supply chain, particularly the 
decisive role of order parameters in attaining well-regulated collaborations of the entire system. Order parameters along with influential elements selections based on servo theory are accomplished with reference to previous studies [50, 51]. Differential equations according to self-organization method of system dynamic theory are established to demonstrate evolutionary process toward a state of cooperative system stability.

\section{Collaboration Model}

With the deepening of technological innovation, competition among corporations is replaced with that among supply chains, and supply chain management has become a popular agenda of many enterprises. Among these, the collaboration capability is regarded as the core competence for accomplishing profit maximization and market share increase.

In practical terms, enterprises in a collaborative supply chain are required to cooperate with each other for winwin development by integrating and optimizing resources involving logistics, fund, information, and commodity, which are of great concern in the e-commerce and express delivery industry. Logistics, conveying the process of procurement, distribution, warehousing, packaging, and so forth, is part of the transaction between supply chain enterprises and customers and ultimately reflects the value of goods and service. The flow of commodity in the trade process shows the ownership transition of the goods from the e-commerce enterprise to customers, while the capital flows are in an opposite direction. Last but not least, flow of information referring to the processes of information collection, transmission, storage, retrieval, and analysis is the basis for regular functions of logistics and capital flow. All in all, the information flow provides accurate messages on the supply chain and the circulation of fund achieves value form transfer of the product, while the flow and logistics complete commodity transfer eventually. Apparently, the four main elements work together to have an impact on the collaborative ability and profitability ability of the e-commerce and express delivery industry supply chain.

Taking synergetics as the guiding ideology, this section analyzes the considering supply chain collaboration from the perspective of resource synergy within the channel for all members' consolidated goal of profit maximization and market share increase. In this case, two order parameters of profitability and interoperability are incurred in predominating the process of resource integration and channel evolution.

3.1. Problem Characteristics and Assumptions. Profitability and collaboration capabilities along with the circulation of commodity, fund, information, and logistics of the ecommerce and express delivery industry should be taken together for accomplishing a collaborative supply chain. Among these, profitability and collaboration capability are order parameters that are key to system evolution, while the rest of the resources involving logistics, information, commodity, and capital are also regarded as indispensable factors for proper functioning.

$P$ is considered as the profitability of e-commerce and express enterprises, while $C$ represents the collaboration abilities. Logistics, fund, information, and commodity factors are expressed as $L, F, I$, and $B$, respectively. Thus, the operational systems of enterprises denoted as $Q$ could be obtained:

$$
\begin{aligned}
& Q_{E}=\left\{P_{E}, C_{E}, L_{E}, F_{E}, I_{E}, B_{E}\right\}, \\
& Q_{D}=\left\{P_{D}, C_{D}, L_{D}, F_{D}, I_{D}, B_{D}\right\},
\end{aligned}
$$

where the subscripts of $E$ and $D$ signify the e-commerce enterprise and express delivery enterprise, separately.

Logic algebra method is connected to model calculations, where " 0 " and " 1 " are applied for demonstrating relations among resource elements of the e-commerce and express delivery industry supply chain. Specifically, if there exist interactions between different features, the result comes to be " 1 ," and, otherwise, the solution of " 0 " would be put forward. Consequently, matrix model illustrating relations among factors could be expressed as

$$
\begin{aligned}
& \begin{array}{llllll}
P_{D} & C_{D} & L_{D} & F_{D} & I_{D} & B_{D}
\end{array} \\
& \begin{array}{l}
P_{E} \\
C_{E} \\
L_{E} \\
F_{E} \\
I_{E} \\
B_{E}
\end{array}\left[\begin{array}{llllll}
a_{11} & a_{12} & a_{13} & a_{14} & a_{15} & a_{16} \\
a_{21} & a_{22} & a_{23} & a_{24} & a_{25} & a_{26} \\
a_{31} & a_{32} & a_{33} & a_{34} & a_{35} & a_{36} \\
a_{41} & a_{42} & a_{43} & a_{44} & a_{45} & a_{46} \\
a_{51} & a_{52} & a_{53} & a_{54} & a_{55} & a_{56} \\
a_{61} & a_{62} & a_{63} & a_{64} & a_{65} & a_{66}
\end{array}\right],
\end{aligned}
$$

where $a_{i j}=\{0,1\}, i, j=1,2,3,4,5,6 . a_{i j}=0$ when elements under observation are unrelated with each other, while $a_{i j}=1$ could be obtained from a contrary result.

3.2. Model Formulation. In this part, interactions of profitability and collaboration capability that act as order parameters and remaining influences regarding logistics, fund, information, and commodity, which are treated as a whole, are investigated through a diverse of matrix model formulations and calculations.

Firstly, we deem $M_{R 1}$ as the interaction of profitability between e-commerce and express delivery enterprises, while $M_{R 2}$ is interrelations of enterprises' collaboration capabilities and $M_{R 3}$ is shown as self-feedback status of logistics, fund, information, and commodity resources. Combining the given parameters and assumptions with (2), we have 


$$
\begin{aligned}
M_{R 1} & =\left[\begin{array}{llllll}
1 & 0 & 0 & 0 & 0 & 0 \\
0 & 0 & 0 & 0 & 0 & 0 \\
0 & 0 & 0 & 0 & 0 & 0 \\
0 & 0 & 0 & 0 & 0 & 0 \\
0 & 0 & 0 & 0 & 0 & 0 \\
0 & 0 & 0 & 0 & 0 & 0
\end{array}\right], \\
M_{R 2} & =\left[\begin{array}{llllll}
0 & 0 & 0 & 0 & 0 & 0 \\
0 & 1 & 0 & 0 & 0 & 0 \\
0 & 0 & 0 & 0 & 0 & 0 \\
0 & 0 & 0 & 0 & 0 & 0 \\
0 & 0 & 0 & 0 & 0 & 0 \\
0 & 0 & 0 & 0 & 0 & 0
\end{array}\right], \\
M_{R 3}= & {\left[\begin{array}{llllll}
0 & 0 & 0 & 0 & 0 & 0 \\
0 & 0 & 0 & 0 & 0 & 0 \\
0 & 0 & 1 & 0 & 0 & 0 \\
0 & 0 & 0 & 1 & 0 & 0 \\
0 & 0 & 0 & 0 & 1 & 0 \\
0 & 0 & 0 & 0 & 0 & 1
\end{array}\right] . }
\end{aligned}
$$

$M_{R 4}$ is defined as interactions between profitability and interoperability of e-commerce and express delivery enterprises then. $M_{R 5}$ signifies the relations between profitability and other resource elements as a whole, while $M_{R 6}$ states the influences of collaboration ability and resource elements similarly. Moreover, $M_{R 7}$ is introduced to show the internal relations among factors of logistics, fund, information, and commodity resources:

$$
\begin{aligned}
M_{R 4} & =\left[\begin{array}{llllll}
0 & 1 & 0 & 0 & 0 & 0 \\
1 & 0 & 0 & 0 & 0 & 0 \\
0 & 0 & 0 & 0 & 0 & 0 \\
0 & 0 & 0 & 0 & 0 & 0 \\
0 & 0 & 0 & 0 & 0 & 0 \\
0 & 0 & 0 & 0 & 0 & 0
\end{array}\right], \\
M_{R 5} & =\left[\begin{array}{llllll}
0 & 0 & 1 & 1 & 1 & 1 \\
0 & 0 & 0 & 0 & 0 & 0 \\
1 & 0 & 0 & 0 & 0 & 0 \\
1 & 0 & 0 & 0 & 0 & 0 \\
1 & 0 & 0 & 0 & 0 & 0 \\
1 & 0 & 0 & 0 & 0 & 0
\end{array}\right],
\end{aligned}
$$

$$
\begin{aligned}
M_{R 6} & =\left[\begin{array}{llllll}
0 & 0 & 0 & 0 & 0 & 0 \\
0 & 0 & 1 & 1 & 1 & 1 \\
0 & 1 & 0 & 0 & 0 & 0 \\
0 & 1 & 0 & 0 & 0 & 0 \\
0 & 1 & 0 & 0 & 0 & 0 \\
0 & 1 & 0 & 0 & 0 & 0
\end{array}\right], \\
M_{R 7}= & {\left[\begin{array}{llllll}
0 & 0 & 0 & 0 & 0 & 0 \\
0 & 0 & 0 & 0 & 0 & 0 \\
0 & 0 & 0 & 1 & 1 & 1 \\
0 & 0 & 1 & 0 & 1 & 1 \\
0 & 0 & 1 & 1 & 0 & 1 \\
0 & 0 & 1 & 1 & 1 & 0
\end{array}\right] . }
\end{aligned}
$$

3.3. Model Calculation and Investigation. According to the matrix models established in Section 3.2, relations of profitability and collaboration ability along with the rest of the resources in the e-commerce and express delivery industry supply chain could be acknowledged by model computing.

Proposition 1. $M_{R i} \times M_{R i}=M_{R i}, i \in\{1,2,3\}$. Self-feedback of order parameters and other resource elements have no impact on system transaction; that is, interrelations within one single factor would not cause system evolution. Mere collaborations of profitability, interoperability, or resource elements with the channel would not help to accomplish synergy across the entire channel.

Proposition 2. $M_{R i} \times M_{R j}=0$ when $i, j \in\{1,2,3\}$ and $i \neq j$. Analogously, interactions would not occur between self-feedbacks of order parameters and resource elements. Profitability, collaboration capability and other resources could be cooperated only if all factors are related with each other.

Proposition 3. $M_{R 1} \times M_{R 7}=M_{R 7} \times M_{R 1}=0, M_{R 2} \times$ $M_{R 7}=M_{R 7} \times M_{R 2}=0$ shows that it is insufficient for the order parameters and resources to exert influences on each other when logistics, fund, information, and commodity are not jointly considered. In other words, only collaborative operations of resource elements could affect enterprises' profitability and interoperability within the channel.

Further calculations to analyze the impacts on resource elements allocated by the order parameters are conducted; we have $M_{R 8}$ and $M_{R 9}$ shown as follows:

$$
\begin{aligned}
M_{R 8}= & M_{R 1} \times M_{R 5}=M_{R 5} \times M_{R 3}=\frac{M_{R 5} \times M_{R 7}}{3} \\
= & {\left[\begin{array}{llllll}
0 & 0 & 1 & 1 & 1 & 1 \\
0 & 0 & 0 & 0 & 0 & 0 \\
0 & 0 & 0 & 0 & 0 & 0 \\
0 & 0 & 0 & 0 & 0 & 0 \\
0 & 0 & 0 & 0 & 0 & 0 \\
0 & 0 & 0 & 0 & 0 & 0
\end{array}\right] }
\end{aligned}
$$




$$
\begin{aligned}
M_{R 9}= & M_{R 2} \times M_{R 6}=M_{R 6} \times M_{R 3}=\frac{M_{R 6} \times M_{R 7}}{3} \\
& =\left[\begin{array}{llllll}
0 & 0 & 0 & 0 & 0 & 0 \\
0 & 0 & 1 & 1 & 1 & 1 \\
0 & 0 & 0 & 0 & 0 & 0 \\
0 & 0 & 0 & 0 & 0 & 0 \\
0 & 0 & 0 & 0 & 0 & 0 \\
0 & 0 & 0 & 0 & 0 & 0
\end{array}\right]
\end{aligned}
$$

Proposition 4. $M_{R 8}$ and $M_{R 9}$, regarded as the impacts of profitability and interoperability put on resources, respectively, indicate that influences of order parameters self-feedback are exerted on resource elements, and profitability and interoperability are affecting the circulation of logistics, fund, information, and commodity. Thus, the order parameters in the supply chain are acting as dominant factors for the evolution of other resources.

The following considerations of $M_{R 10}, M_{R 11}$, and $M_{R 12}$ are taken into account to demonstrate the strong power of order parameters influencing other resources.

$$
\begin{aligned}
M_{R 10}=M_{R 1}+M_{R 4}=\left[\begin{array}{llllll}
1 & 1 & 0 & 0 & 0 & 0 \\
1 & 0 & 0 & 0 & 0 & 0 \\
0 & 0 & 0 & 0 & 0 & 0 \\
0 & 0 & 0 & 0 & 0 & 0 \\
0 & 0 & 0 & 0 & 0 & 0 \\
0 & 0 & 0 & 0 & 0 & 0
\end{array}\right], \\
M_{R 11}=M_{R 2}+M_{R 4}=\left[\begin{array}{llllll}
0 & 1 & 0 & 0 & 0 & 0 \\
1 & 1 & 0 & 0 & 0 & 0 \\
0 & 0 & 0 & 0 & 0 & 0 \\
0 & 0 & 0 & 0 & 0 & 0 \\
0 & 0 & 0 & 0 & 0 & 0 \\
0 & 0 & 0 & 0 & 0 & 0
\end{array}\right], \\
M_{R 12}=M_{R 10} \times M_{R 5}=M_{R 11} \times M_{R 6} \\
=\left[\begin{array}{llllll}
0 & 0 & 1 & 1 & 1 & 1 \\
0 & 0 & 1 & 1 & 1 & 1 \\
0 & 0 & 0 & 0 & 0 & 0 \\
0 & 0 & 0 & 0 & 0 & 0 \\
0 & 0 & 0 & 0 & 0 & 0 \\
0 & 0 & 0 & 0 & 0 & 0
\end{array}\right]=M_{R 8}+M_{R 9}, \\
\end{aligned}
$$

where $M_{R 10}$ and $M_{R 11}$ describe the interrelations within the parameters, while $M_{R 12}$ is resolved as influences on resource elements exerted by cooperative order parameters.
Proposition 5. When there exist interactions between the two parameters, it would function better for promoting resource elements' collaborative operations.

Correspondingly, resources elements' effects on profitability and collaboration capability are discussed, expressed as $M_{R 13}$ and $M_{R 14}$, respectively:

$$
\begin{aligned}
M_{R 13}= & M_{R 5} \times M_{R 1}=M_{R 3} \times M_{R 5}=\frac{M_{R 7} \times M_{R 5}}{3} \\
= & {\left[\begin{array}{llllll}
0 & 0 & 0 & 0 & 0 & 0 \\
0 & 0 & 0 & 0 & 0 & 0 \\
1 & 0 & 0 & 0 & 0 & 0 \\
1 & 0 & 0 & 0 & 0 & 0 \\
1 & 0 & 0 & 0 & 0 & 0 \\
1 & 0 & 0 & 0 & 0 & 0
\end{array}\right], } \\
M_{R 14} & M_{R 6} \times M_{R 2}=M_{R 3} \times M_{R 6}=\frac{M_{R 7} \times M_{R 6}}{3} \\
= & {\left[\begin{array}{llllll}
0 & 0 & 0 & 0 & 0 & 0 \\
0 & 0 & 0 & 0 & 0 & 0 \\
0 & 1 & 0 & 0 & 0 & 0 \\
0 & 1 & 0 & 0 & 0 & 0 \\
0 & 1 & 0 & 0 & 0 & 0 \\
0 & 1 & 0 & 0 & 0 & 0
\end{array}\right] . }
\end{aligned}
$$

Proposition 6. Interrelations of order parameters and resources elements would have an impact on order parameters in their role of channel collaboration. Reactions of logistics, fund, information, and commodity occur in the face of profitability and interoperability of the e-commerce and express delivery industry supply chain.

$M_{R 15}$ is introduced to further analyze resource elements' counteractions on order parameters; (10) and (11) acquired accordingly show enhanced influences exerted on order parameters:

$$
M_{R 15}=M_{R 3}+M_{R 7}=\left[\begin{array}{llllll}
0 & 0 & 0 & 0 & 0 & 0 \\
0 & 0 & 0 & 0 & 0 & 0 \\
0 & 0 & 1 & 1 & 1 & 1 \\
0 & 0 & 1 & 1 & 1 & 1 \\
0 & 0 & 1 & 1 & 1 & 1 \\
0 & 0 & 1 & 1 & 1 & 1
\end{array}\right] \text {, }
$$




$$
\begin{aligned}
& M_{R 15} \times M_{R 5}=4 \times\left[\begin{array}{cccccc}
0 & 0 & 0 & 0 & 0 & 0 \\
0 & 0 & 0 & 0 & 0 & 0 \\
1 & 0 & 0 & 0 & 0 & 0 \\
1 & 0 & 0 & 0 & 0 & 0 \\
1 & 0 & 0 & 0 & 0 & 0 \\
1 & 0 & 0 & 0 & 0 & 0
\end{array}\right]=4 M_{R 13} \text {, } \\
& M_{R 15} \times M_{R 6}=4 \times\left[\begin{array}{cccccc}
0 & 0 & 0 & 0 & 0 & 0 \\
0 & 0 & 0 & 0 & 0 & 0 \\
0 & 1 & 0 & 0 & 0 & 0 \\
0 & 1 & 0 & 0 & 0 & 0 \\
0 & 1 & 0 & 0 & 0 & 0 \\
0 & 1 & 0 & 0 & 0 & 0
\end{array}\right]=4 M_{R 14} \text {. }
\end{aligned}
$$

Proposition 7. Intensive effects of order parameters on resources, reflected as $4 M_{R 13}$ and $4 M_{R 14}$, could be attained through closely related resource elements $M_{R 15}$. Counteractions of resources involving logistics, fund, information, and commodity would be enhanced to expedite the progress toward a cooperative direction of the e-commerce and express delivery supply chain, of which profitability and collaboration capability are improved certainly.

\section{Evolutionary Model}

4.1. Model Formulation. The evolution of the supply chain from disordered to ordered state is associated with the interrelations of channel members and factors within the system along with external stochastic fluctuations. Mutual influences between resources along with system changes could be expressed by the following functions [35]:

$$
\begin{aligned}
& \frac{d X}{d t}=-a_{1} X+b_{1}(Y, Z, R)+F(t) \\
& \frac{d Y}{d t}=-a_{2} Y+b_{2}(X, Z, R)+F(t) \\
& \frac{d Z}{d t}=-a_{3} Z+b_{3}(X, Y, R)+F(t) \\
& \frac{d R}{d t}=-a_{4} R+b_{4}(X, Y, Z)+F(t),
\end{aligned}
$$

where $X, Y, Z, R$ represent resource elements and $a_{1}, a_{2}$, $a_{3}, a_{4}$ reflect the factors' change rate which is affected by interrelationship of resources, expressed as $b_{1}, b_{2}, b_{3}, b_{4} . F(t)$ is regarded as the stochastic fluctuation which is the function of time $t$.

In the e-commerce and express delivery industry supply chain, similarly, the circulation of logistics, fund, information, and commodity, holding intricate relations with each other, are considered as main resource elements of the channel for system progress, so that we have the corresponding self-organizing dynamic equation shown as

$$
\begin{aligned}
& \frac{d L}{d t}=-a_{1} L+b_{1}(F, I, B)+F(t) \\
& \frac{d F}{d t}=-a_{2} F+b_{2}(L, I, B)+F(t) \\
& \frac{d I}{d t}=-a_{3} I+b_{3}(L, F, B)+F(t) \\
& \frac{d B}{d t}=-a_{4} B+b_{4}(L, F, I)+F(t),
\end{aligned}
$$

where $L, F, I, B$ represent resource elements regarding logistics, fund, information, and commodity, respectively, and the rest of the parameters share the same meaning with equations (12).

In the process of evolution from disordered to an ordered status, order parameters play a decisive role in the structure formulation of the entire system. The order parameters and other resource elements are depending on each other as well as interacting with each other, leading to the emerging of a new order with self-organized procedure [52]. Taking the dominant function of the order parameters into account, it is adequate to merely analyze the evolution law of the profitability and interoperability for getting an idea of the supply chain's evolutionary mechanism.

4.2. Model Analysis. Define $P$ and $C$, regarded as the profitability and collaboration ability, respectively, as the order parameters and $S$ signifies the resource elements' system that deems the remaining factors involving logistics, fund, information, and commodity as a whole. $r$ means the profit parameters; $\theta_{1}$ and $\theta_{2}$ represent the damping coefficients of $P$ and $C$, respectively. $\alpha_{1}$ is the interaction force of profitability and interoperability, $\alpha_{2}$ denotes the influence coefficients of $C$ and $P$, and $\alpha_{3}$ indicates resource elements' impact on collaboration capability. $\phi$ stands for the attenuation coefficient of profitability and $\beta_{1}$ and $\beta_{2}$ are influential factors of resource elements affected by profitability and interoperability separately, while $\beta_{3}$ states the self-feedback parameter of resources and $\beta_{4}$ is expressed as the combined effect of profitability and collaboration ability exerted on resource factors. According to the self-organization principle of synergetics, the evolutionary process of the e-commerce and express delivery supply chain immediately impacted by the order parameters could be obtained as follows:

$$
\begin{aligned}
& \frac{d P}{d t}=\left(r-\theta_{1}\right) P-\phi P^{2}+\alpha_{1} P C+F(t) \\
& \frac{d C}{d t}=-\theta_{2} C+\alpha_{2} P^{2}+a_{3} S \\
& \frac{d S}{d t}=\beta_{1} P+\beta_{2} C+\beta_{3} S+\beta_{4} P C
\end{aligned}
$$

where the first two equations in the above equation set signify the decisive role of the parameters in the system evolution 


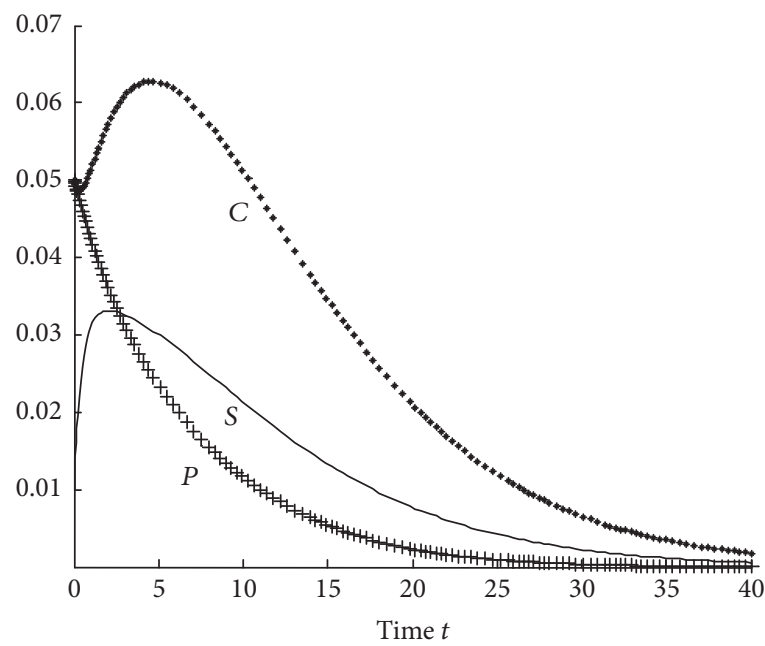

(a) The system is stable and $f(t)=0$

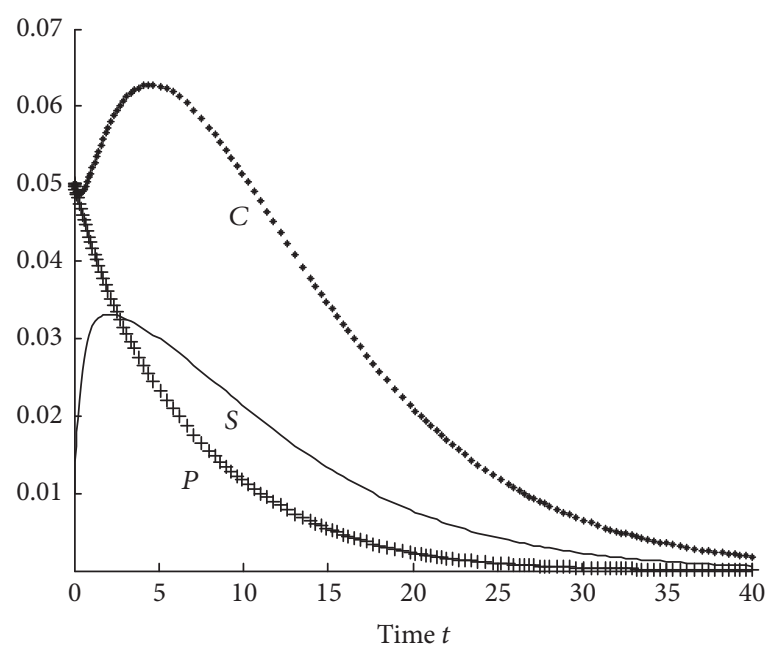

(b) The system is stable and $f(t)=0.001$

FIGURE 1: Variation trends of parameters and resource elements under system stability.

sequentially, while the last one is introduced to illustrate the order parameters' impact on resource elements.

During the progressive process of the e-commerce and express industry supply chain, the system remains stable under the conditions that the order parameters, that is, profitability and interoperability, stay unchanged and other resources are also invariable. The balance point turns out to be $(0,0,0)$ accordingly where $d P / d t=0, d C / d t=0, d S / d t=0$ and the feature matrix accordingly could be attained as

$$
J=\left[\begin{array}{ccc}
r-\theta_{1}-2 \phi P+\alpha_{1} C & \alpha_{1} P & 0 \\
2 \alpha_{2} P & -\theta_{2} & \alpha_{3} \\
\beta_{1}+\beta_{4} C & \beta_{2}+\beta_{4} P & \beta_{3}
\end{array}\right] .
$$

Then, the feature matrix in the balance point could be expressed as

$$
A=\left|\begin{array}{ccc}
\lambda-\left(r-\theta_{1}\right) & 0 & 0 \\
0 & \lambda+\theta_{2} & -\alpha_{3} \\
-\beta_{1} & -\beta_{2} & \lambda-\beta_{3}
\end{array}\right|=0 .
$$

Based on (16), the characteristic roots could be calculated to be $\lambda_{1}=r-\theta_{1}$ and $\lambda_{2,3}=\left[\beta_{3}-\theta_{2} \pm \sqrt{\left(\theta_{2}+\beta_{3}\right)^{2}+4 \alpha_{3} \beta_{2}}\right] / 2$. The balance point of the system would be stable only if all characteristic roots are negative according to the principle of differential equation.

Proposition 8. (1) When $r<\theta_{1}$ and $\beta_{3}-\theta_{2}+$ $\sqrt{\left(\theta_{2}+\beta_{3}\right)^{2}+4 \alpha_{3} \beta_{2}}<0$ are satisfied, the system turns out to be steady. However, the e-commerce and express industry supply chain is under a low level of stable circumstance that resources have not been fully integrated and cooperated, leading to incomplete collaboration which is lack of strength to bring about channel transition.
(2) Conversely, when $r \geq \theta_{1}$ or $\beta_{3}-\theta_{2}+$ $\sqrt{\left(\theta_{2}+\beta_{3}\right)^{2}+4 \alpha_{3} \beta_{2}} \geq 0$ occurs, the supply chain would suffer from instability. At this moment, external random fluctuation would take effect to make the system evolved with the accompanied with the self-organization evolution, forming a more stable structure. In particular, there would be a demarcation point arising if $r=\theta_{1}$ or $\beta_{3}-\theta_{2}+\sqrt{\left(\theta_{2}+\beta_{3}\right)^{2}+4 \alpha_{3} \beta_{2}}=0$ is fulfilled, and the whole channel stands ready to make a difference if affected by even a minor change. Additionally, when the characteristic roots $\lambda=0, r>\theta_{1}$ or $\beta_{3}-\theta_{2}+\sqrt{\left(\theta_{2}+\beta_{3}\right)^{2}+4 \alpha_{3} \beta_{2}}>0$ should be attained, and the system collaboration gradually enhanced for system transition to accomplish sophisticated order.

4.3. Numerical Analysis. We concluded from Proposition 8 that $r, \theta_{1}, \theta_{2}, \alpha_{3}, \beta_{2}, \beta_{3}$ are of vital significance of attaining system stability. Thence, numerical analysis in this section takes diverse values of the parameters under various conditions, aiming at providing an intuitive idea of the results.

4.3.1. System Stability Analysis. Proposition 8 has illustrated that under the condition of $r<\theta_{1}$ and $\beta_{3}-\theta_{2}+$ $\sqrt{\left(\theta_{2}+\beta_{3}\right)^{2}+4 \alpha_{3} \beta_{2}}<0$, the supply chain system stays unchanged with a relatively low level of ordered state. Relevant parameters affecting the system stability are deemed as follows: $r=0.1, \theta_{1}=0.3, \theta_{2}=0.4, \alpha_{1}=1.2, \alpha_{2}=0.9$, $\alpha_{3}=0.8, \phi=0.6, \beta_{1}=0.8, \beta_{2}=0.6, \beta_{3}=-2, \beta_{4}=$ 1.5 , and corresponding simulation curves of profitability, collaboration capability, and resource integration of the ecommerce and express delivery industry supply chain could be obtained by MATLAB application.

Figure 1(a) reflects the factors' various conditions in the absence of the stochastic fluctuation, while Figure 1(b) shows 


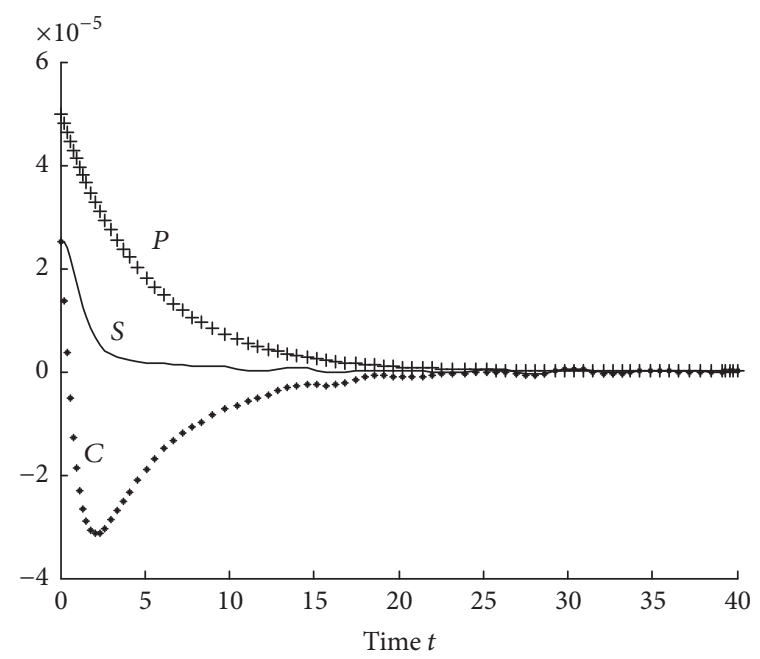

(a) The system is stable and $\alpha_{3}=-2$

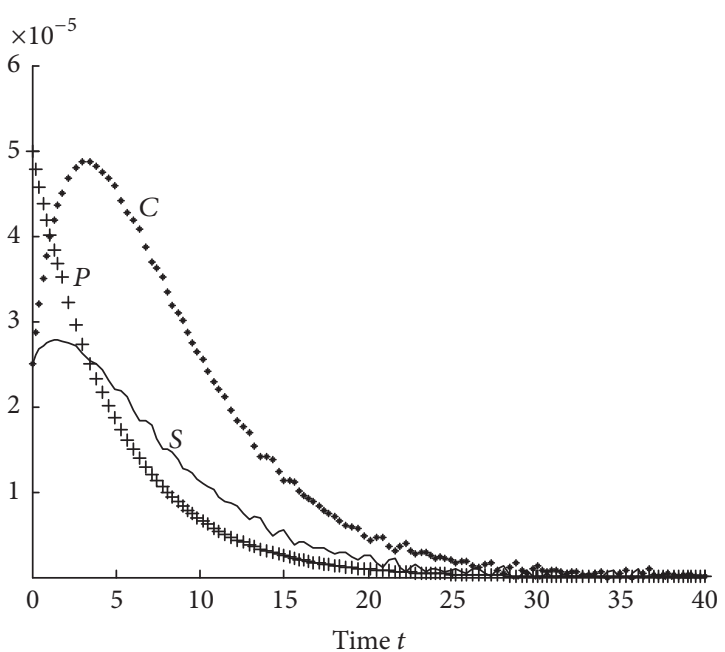

(b) The system is stable and $\alpha_{3}=1.5$

FIGURE 2: Variation trends of parameters and resource elements under the influence of resource integration.

that when $f(t)=0.001$. Apparently, whether the external fluctuation exists or not, the variation trends of all variables keep inclining to zero generally when $r<\theta_{1}$ and $\beta_{3}-\theta_{2}$ $+\sqrt{\left(\theta_{2}+\beta_{3}\right)^{2}+4 \alpha_{3} \beta_{2}}<0$ are satisfied. Specifically, even though a minor change externally could make the curves drift off the courses in Figure 1(b), eventually the solutions gradually round toward zero with the increase of $t$ as time goes on.

Influences on collaboration ability exerted by resource elements are given numerically as well. Solution curves under different values of $\alpha_{3}$, which indicates resource elements' impact on collaboration capability, are shown as Figures 2(a) and 2(b).

Figure 2(a) shows that, under the situation that $\alpha_{3}=$ $-2<0$, when resource elements have a negative impact on interoperability, it suggests inadequate resources integration of the supply chain which result in poor profitability inevitability, and the collaboration ability even suffers from minus at the very beginning. With the increase of $t$, the order parameters have strengthened their power in leading the system positively, so that the collaboration capability gradually tends to evolve and keep steady since then. On the other hand, when $\alpha_{3}$ rises from -2 to 1.5 in Figure 2(b), interoperability is constantly under active guidance and is enhanced as a result.

4.3.2. System Instability Analysis. The e-commerce and express delivery industry supply chain demonstrates unstability when $r \geq \theta_{1}$ or $\beta_{3}-\theta_{2}+\sqrt{\left(\theta_{2}+\beta_{3}\right)^{2}+4 \alpha_{3} \beta_{2}} \geq 0$ is satisfied. Taking $r>\theta_{1}$ into account, firstly, we have Figures 3(a) and 3(b).

Figure 3(a) suggests a growth of profitability of the supply chain when the profit parameter is bigger than the damping coefficients, that is, $r>\theta_{1}$. With time extending, the profitability and interoperability acting as order parameters that are dominant in the process of system evolution work actively in guiding the whole channel toward a steady status along with the smoothly varied curves. In Figure 3(b), however, there are tiny effects of external random fluctuation existing when $f(t)=0.0001$, and great change has taken place in all the three solution curves with the order parameters losing their function in improving the coordination and cooperation of the supply chain, and the entire system is at the brink of a disordered condition. Hence, alternatives, other than profitability and collaboration capability, should be put forward to replace the original order parameters, for the efficient evolution of the e-commerce and express delivery industry supply chain.

The process of system evolution under condition $\beta_{3}-$ $\theta_{2}+\sqrt{\left(\theta_{2}+\beta_{3}\right)^{2}+4 \alpha_{3} \beta_{2}}>0$ is discussed subsequently with parameter setting being presented as $r=0.1, \theta_{1}=0.3$, $\theta_{2}=1.2, \alpha_{1}=1.2, \alpha_{2}=0.9, \alpha_{3}=0.8, \phi=0.6, \beta_{1}=0.8$, $\beta_{2}=2, \beta_{3}=-2, \beta_{4}=1.5$.

Figure 4(a) describes the tendency of system evolution of all factors involving the profitability, interoperability, and other resource elements of the e-commerce and express delivery industry supply chain when $\beta_{3}-\theta_{2}+$ $\sqrt{\left(\theta_{2}+\beta_{3}\right)^{2}+4 \alpha_{3} \beta_{2}}>0$ is fulfilled. As $\theta_{2}$ and $\beta_{2}$ hold a high value, so that the damping coefficient increases with the decrease of the collaboration ability, leading to a decrement of its influence on resource elements. Figure 4(b) is drawn up when there exists external stochastic fluctuation; that is, $f(t)=0.0001$; the order parameters have functioned actively in guiding the system progressed and it works eventually as all factors within the channel evolved with all solution curves going smoothly over time. In addition, compared with Figure 4(a), values of the same points of curves in Figure 4(b) turn out to be higher, which implies a system transition with a higher level of ordered status of the supply chain ultimately. 


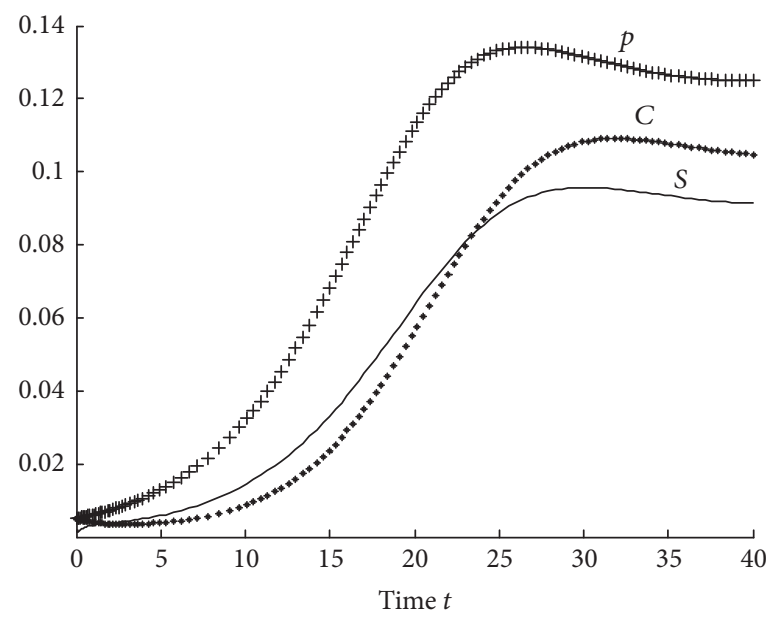

(a) $f(t)=0$

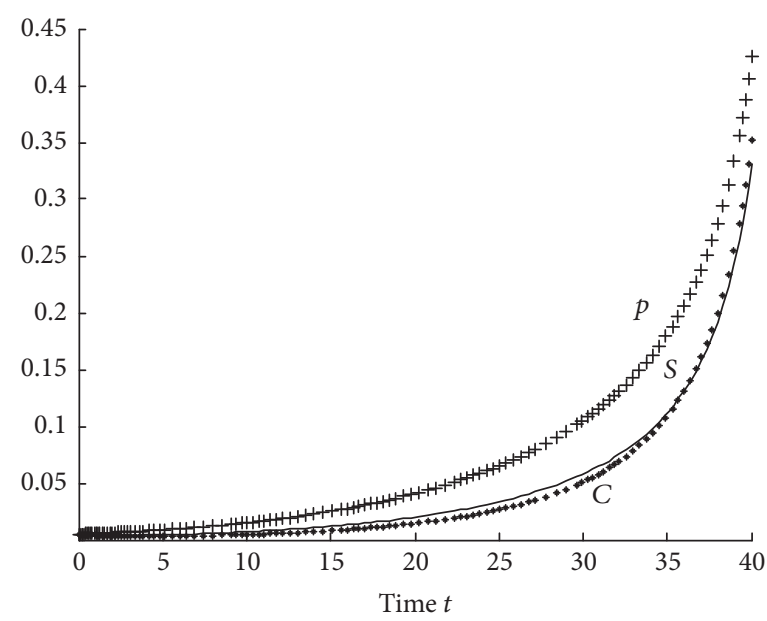

(b) $f(t)=0.0001$

FIGURE 3: Variation trends of parameters and resource elements under system instability (when $\left.r>\theta_{1}\right)$.

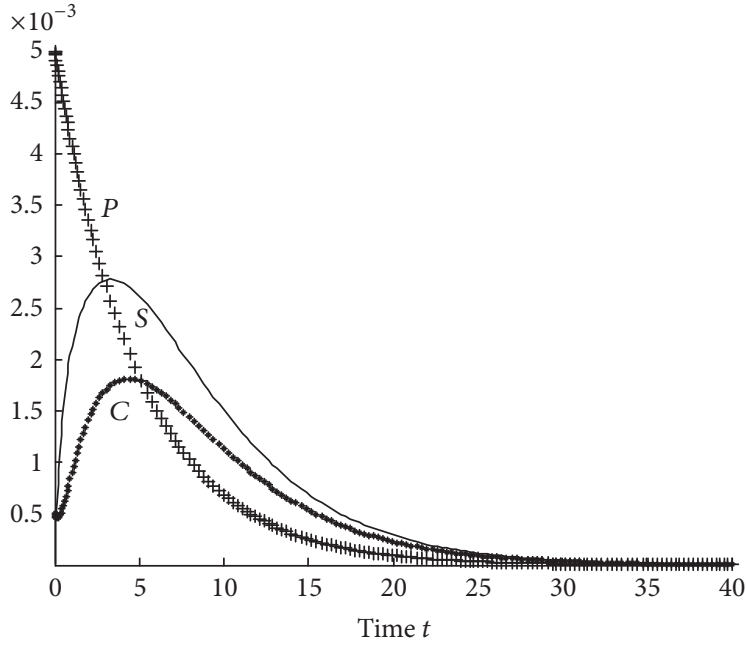

(a) $f(t)=0$

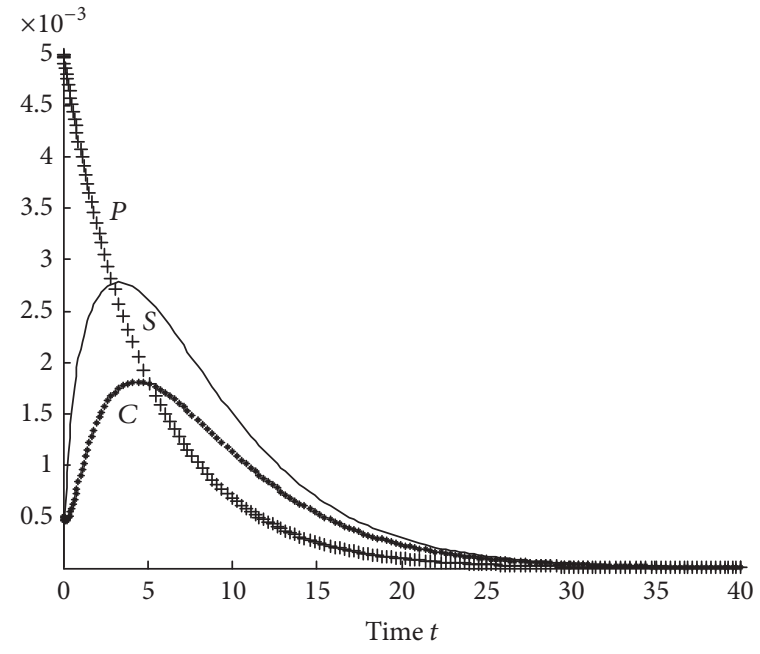

(b) $f(t)=0.0001$

FIGURE 4: Variation trends of parameters and resource elements under system instability $\left(\right.$ when $\left.\beta_{3}-\theta_{2}+\sqrt{\left(\theta_{2}+\beta_{3}\right)^{2}+4 \alpha_{3} \beta_{2}}>0\right)$.

\section{Conclusions and Future Research}

This paper investigates the e-commerce and express delivery industry supply chain based on servo theory of synergetics. Self-organization principle of system dynamics method is introduced to analyze the intra- and interrelations of all influential elements in system evolution. Among these, profitability and collaboration ability, acting as order parameters according to servo theory, have played a decisive role in the system evolution. Interactions of order parameters and the rest of the resource elements are discussed and the order parameters' function in channel transition is emphasized. Furthermore, numerical analysis is employed to give an illustrative idea of the results. Main concluding remarks are summarized as follows.

(1) The profitability and collaboration capability of the e-commerce and express delivery industry supply chain work efficiently, only if the rest of the resource elements regarding logistics, fund, information, and commodity are coordinated. Similarly, the resource factors could affect the order parameters on the premise of their own collaboration (Propositions 1, 2, and 3).

(2) Order parameters of profitability and interoperability exert influences on resource elements, which in turn have reactions on order parameters as well. While the order parameters keep the dominant role in the supply chain, enhanced logistics, fund, information, and commodity resources have strong reflections on the profitability and collaboration ability, resulting in the regular operation and cooperative development of the entire channel (Propositions $4,5,6$, and 7 ).

(3) In the initial stage of e-commerce and express delivery industry collaborative operations, the interoperability has 
been so week to bring about supply chain transitions and the system stays in a relatively low level of stability, and external stochastic fluctuations have no impact on system balance (Proposition 8, Figure 1). With the enhancement of resource integration, the collaboration capability transition occurs when other resource elements present closer cooperative and coordinated relations (Figure 2).

(4) External stochastic fluctuation works to generate structural changes of the system, leading to the disordered status of the supply chain. The profitability and collaboration capability, what is worse, lose their advantage when acting as order parameters to guide the system (Figure 3). While the interoperability enhanced, the supply chain is available for an evolution toward a higher ordered state under the influence of external stochastic fluctuation (Proposition 8, Figure 4).

This paper focuses on the collaboration and evolution of the e-commerce and express delivery industry supply chain. Existing researches accounting intra- and interrelations among resources of a supply chain conveying two or more industries are rare, which makes our study a path-breaking attempt of e-commerce and express delivery industry resource elements' relations investigation through theoretical models. We have indeed investigated horizontal collaborations among various elements and proved that all resources are mutually interacted by combining the two closely related businesses in an entire cooperative supply chain.

In practical, it is imperative for e-commerce and express delivery enterprises to accomplish coordinated development as both industries are interdependent on each other. To illustrate, $60 \%$ of express delivery business in China is derived from online shopping in 2013 and the proportion was reported to increase to $80 \%$ in the following year. However, while e-commerce stands out as an innovative industry that facilitate the interaction of logistics, fund, information, and commodity, it comes to a halt due to the low efficiency and unqualified technique level of express delivery as the complaint rates of express delay and unfavourable delivery service in 2015 were reported to have a growth of $12.8 \%$ and $65.8 \%$, respectively. In terms of current contradictions between the e-commerce and express delivery industry that cause the whole channel failing to collaborate efficiently, we conclude our work along with its results of significant references for e-commerce and express delivery enterprises and industries with similar experiences in integrating and optimizing resources.

There is still room for further extensions and improvements for system evolution. As our work mainly focuses on the cooperation and coordination of e-commerce and express delivery enterprises within the supply chain, external interferences involving governmental policies, market demand, customer preferences, and loyalty are somewhat overlooked, which indeed mean a lot to the collaborative supply chain, for instance, when governmental involvement via financial instruments functions on either member of the supply chain, the relations, and interaction of profitability and collaboration capability within the chain would be interfered as well as the process of channel evolution. Further, more appropriate and comprehensive collaboration and evolutionary models of e-commerce and express delivery industry supply chain are worth discussing in the future works.

\section{Competing Interests}

The authors declare that they do not have any commercial or associative interests that represent a conflict of interests in connection with this work.

\section{Acknowledgments}

This work was supported by the National Natural Science Foundation of China (71172182, 71302122, U1509220), the Humanities and Social Sciences Research Project of Ministry of Education (14YJC630154), the National Natural Science Foundation of Ningbo (2014A610174), the Electronic Commerce Research of Ningbo Dahongying University (1320151003), and the Soft Science Foundation of Ningbo (2016A10059).

\section{References}

[1] China Electronic Commerce Center, Global Cross-Border Electronic Commerce Report 2013, China Electronic Commerce Center, 2014, http://www.100ec.cn/detail-6181892.html.

[2] D. Y. Zhang, E-Commerce Development Index of China Ranks, Chinese Electronics News, 2014, http://epaper.cena.com .cn/content/2014-08/12/content_342510.htm.

[3] H. C. Wang and H. Q. Sun, "Re-engineering of enterprise physical distribution system under e-commerce environment," Chinese Journal of Management Science, vol. 8, pp. 797-802, 2000.

[4] Y. X. Yang and G. G. Zhou, "A quantifying synergy model for closed loop supply chain network integration," Journal of Industrial Engineering and Engineering Management, vol. 26, no. 4, pp. 112-118, 2012.

[5] K. Xu, Y. Dong, and Y. Xia, “Too little' or 'Too late': the timing of supply chain demand collaboration," European Journal of Operational Research, vol. 241, no. 2, pp. 370-380, 2015.

[6] Y. P. Li and S. H. Ma, "Research on multi-supplier horizontally synchronization based on space-constrained construction supply chain," Chinese Journal of Management Science, vol. 21, no. 1, pp. 111-117, 2013.

[7] Y. S. Wu, "Evolution model of low carbon supply chain collaborative operation," Operations Research and Management Science, vol. 23, no. 2, pp. 124-132, 2014.

[8] D. Luzzini, E. Brandon-Jones, A. Brandon-Jones, and G. Spina, "From sustainability commitment to performance: the role of intra- and inter-firm collaborative capabilities in the upstream supply chain," International Journal of Production Economics, vol. 165, article no. 6023, pp. 51-63, 2015.

[9] H. Akkermans, P. Bogerd, and J. Van Doremalen, "Travail, transparency and trust: a case study of computer-supported collaborative supply chain planning in high-tech electronics," European Journal of Operational Research, vol. 153, no. 2, pp. 445-456, 2004.

[10] C. J. Corbett and P. R. Kleindorfer, "Environmental management and operations management: introduction to the third special issue," Production and Operations Management, vol. 12, no. 3, pp. 287-289, 2003.

[11] L. M. Ascencio, R. G. González-Ramírez, L. A. Bearzotti, N. R. Smith, and J. F. Camacho-Vallejo, "A collaborative supply chain 
management system for a maritime port logistics chain," Journal of Applied Research and Technology, vol. 12, no. 3, pp. 444-458, 2014.

[12] U. Ramanathan and A. Gunasekaran, "Supply chain collaboration: impact of success in long-term partnerships," International Journal of Production Economics, vol. 147, pp. 252-259, 2014.

[13] H. Yu and F. P. Chen, "Operation mode selection of automotive inbound logistics based on supply chain collaboration," System Engineering-Theory \& Practice, vol. 31, no. 7, pp. 1231-1239, 2011.

[14] C. Eksoz, S. A. Mansouri, and M. Bourlakis, "Collaborative forecasting in the food supply chain: a conceptual framework," International Journal of Production Economics, vol. 158, pp. 120135, 2014.

[15] Z. R. David, A. Nait-Sidi-Moh, D. Durand, and F. Jérôme, "Using Internet of Things Technologies for a collaborative supply chain: application to tracking of pallets and containers," Procedia Computer Science, vol. 56, pp. 550-557, 2015.

[16] E. Rabinovich, A. M. Knemeyer, and C. M. Mayer, "Why do Internet commerce firms incorporate logistics service providers in their distribution channels? the role of transaction costs and network strength," Journal of Operations Management, vol. 25, no. 3, pp. 661-681, 2007.

[17] J. P. Qiu and E. M. Song, "Innovation of logistics management in electronic business," China Soft Science, vol. 4, pp. 107-110, 2002.

[18] Z. D. Gnimpieba, N. S. Ahmed, and D. Durand, "Using Internet of things technologies for a collaborative supply chain: application to tracking of pallets and containers," Procedia Computer Science, vol. 56, pp. 550-557, 2015.

[19] C. Araneda-Fuentes, L. J. Lustosa, and S. Minner, "A contract for coordinating capacity decisions in a business-to-business (B2B) supply chain," International Journal of Production Economics, vol. 165, article no. 6035, pp. 158-171, 2015.

[20] Q. Lu and N. Liu, "Effects of e-commerce channel entry in a two-echelon supply chain: a comparative analysis of singleand dual-channel distribution systems," International Journal of Production Economics, vol. 165, pp. 100-111, 2015.

[21] Y. Y. Yang, Electronic commerce and the private express logistics win-win development mode research [M.S. thesis], Dalian Maritime University, 2012.

[22] L. W. Bao, Y. C. Huang, Z. J. Ma, J. Zhang, and Q. C. Lv, "On the supply chain management supported by E-commerce service platform for agreement based circulation of fruits and vegetables," Physics Procedia, vol. 33, pp. 1957-1963, 2012.

[23] S. Kurnia, R. J. Karnali, and M. M. Rahim, "A qualitative study of business-to-business electronic commerce adoption within the Indonesian grocery industry: a multi-theory perspective," Information \& Management, vol. 52, no. 4, pp. 518-536, 2015.

[24] K. N. S. Iyer, R. Germain, and C. Claycomb, "B2B e-commerce supply chain integration and performance: a contingency fit perspective on the role of environment," Information \& Management, vol. 46, no. 6, pp. 313-322, 2009.

[25] J. W. Zhong, J. N. Wu, and S. Mei, "Application capability of ebusiness theory development and empirical validation," Journal of Management Science in China, vol. 13, no. 12, pp. 61-75, 2010.

[26] T. J. Feng and G. H. Gong, "Research on electronic commercialized SCM of automobile industry," China Soft Science, vol. 2, pp. 105-107, 2001.

[27] C. J. Wang, "Managing material and information flows in supply chain," Chinese Journal of Management Science, vol. 8, no. 4, pp. $16-23,2000$.
[28] X. D. Wang and T. Zhou, "About interaction among information flow, logistics and fund flow of electronic business," Science \& Technology Progress and Policy, vol. 4, pp. 136-138, 2002.

[29] S. B. Xu, "The theory of commodity material flow," Management World, vol. 7, pp. 1-9, 2009.

[30] S. Z. Bai and W. L. Wang, Research on Resource Flow of Complex Adaptive System in Supply Chain, Science Press, Beijing, China, 2009.

[31] R. H. Deng, X. J. Chen, and P. H. Liu, "Collaborative models research on collaboration systems in farm-produce circulation," System Engineering-Theory \& Practice, vol. 7, pp. 59-65, 2006.

[32] L. Z. Tong and C. M. Gu, "Research on 5F model in supply chain management," Management World, vol. 6, pp. 184-185, 2013.

[33] Q. Xu, "The integrative and collaborative services innovation management of supply chain logistics finance," Chinese Business and Market, vol. 8, pp. 29-32, 2009.

[34] A. Soylu, C. Oruç, M. Turkay, K. Fujita, and T. Asakura, "Synergy analysis of collaborative supply chain management in energy systems using multi-period MILP," European Journal of Operational Research, vol. 174, no. 1, pp. 387-403, 2006.

[35] X.-W. Huang and M.-S. He, "Self-organization evolution model of supply chain resources synergy," Journal of Nanjing University of Science and Technology, vol. 34, no. 1, pp. 36-39, 2010.

[36] M. Cao and Q. Zhang, "Supply chain collaboration: impact on collaborative advantage and firm performance," Journal of Operations Management, vol. 29, no. 3, pp. 163-180, 2011.

[37] H. Haken, Synergetic: The Mysteries of Nature, vol. 97, Shanghai Translation Publishing House, Shanghai, China, 2001.

[38] H. Haken, "Synergetics of brain function," International Journal of Psychophysiology, vol. 60, no. 2, pp. 110-124, 2006.

[39] M. M. Huang, "Evolutionary game analysis of cooperation mechanism for collaborative product development in supply chain," Chinese Journal of Management Science, vol. 18, no. 6, pp. 155-162, 2010.

[40] M. Nakano, "Collaborative forecasting and planning in supply chains: the impact on performance in Japanese manufacturers," International Journal of Physical Distribution \& Logistics Management, vol. 39, no. 2, pp. 84-105, 2009.

[41] Z. T. Fan, "Analysis of the internal coordination process of the formation of core competence," Science and Technology Management Research, vol. 3, pp. 25-28, 2000.

[42] V. B. Kreng and F.-T. Chen, "The benefits of a cross-docking delivery strategy: a supply chain collaboration approach," Production Planning \& Control, vol. 19, no. 3, pp. 229-241, 2008.

[43] B. K. Bahinipati, A. Kanda, and S. G. Deshmukh, "Horizontal collaboration in semiconductor manufacturing industry supply chain: an evaluation of collaboration intensity index," Computers \& Industrial Engineering, vol. 57, no. 3, pp. 880-895, 2009.

[44] H. Haken, Information and Self-Organization: A Macroscopic Approach to Complex System, vol. 40 of Springer Series in Synergetics, Springer, New York, NY, USA, 1988.

[45] T. Wu, Self-Organization Methodology Research, Tsinghua University Press, Beijing, China, 2001.

[46] H. C. Co and F. Barro, "Stakeholder theory and dynamics in supply chain collaboration," International Journal of Operations \& Production Management, vol. 29, no. 6, pp. 591-611, 2009.

[47] M. Cedillo-Campos and C. Sánchez-Ramírez, "Dynamic selfassessment of supply chains performance: an emerging market approach," Journal of Applied Research and Technology, vol. 11, no. 3, pp. 338-347, 2013. 
[48] J. Wilson, J. Hill, M. Kersula et al., "Costly information and the evolution of self-organization in a small, complex economy," Journal of Economic Behavior \& Organization, vol. 90, pp. S76S93, 2013.

[49] L. Biggiero and P. P. Angelini, "Hunting scale-free properties in $\mathrm{R} \& \mathrm{D}$ collaboration networks: self-organization, power-law and policy issues in the European aerospace research area," Technological Forecasting and Social Change, vol. 94, no. 5, pp. 21-43, 2015.

[50] Q. R. Xu and Z. X. Xie, "Study of firm's innovation synergy and the evolvement model," Studies In Science of Science, vol. 22, no. 3, pp. 327-332, 2004.

[51] P. J. Daugherty, R. G. Richey, S. E. Genchev, and H. Chen, "Reverse logistics: superior performance through focused resource commitments to information technology," Transportation Research Part E: Logistics and Transportation Review, vol. 41, no. 2, pp. 77-92, 2005.

[52] H. Haken, "Synergetics of brain function," International Journal of Psycho Physiology, vol. 60, no. 2, pp. 110-124, 2006. 


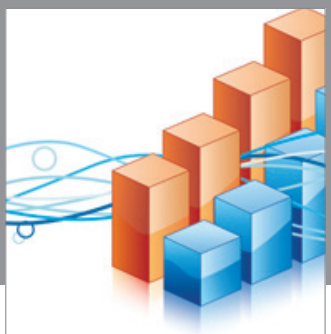

Advances in

Operations Research

vatem alat4

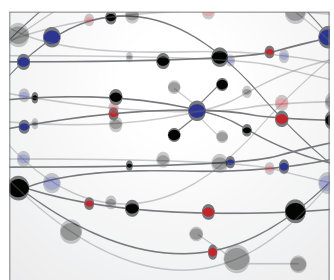

\section{The Scientific} World Journal
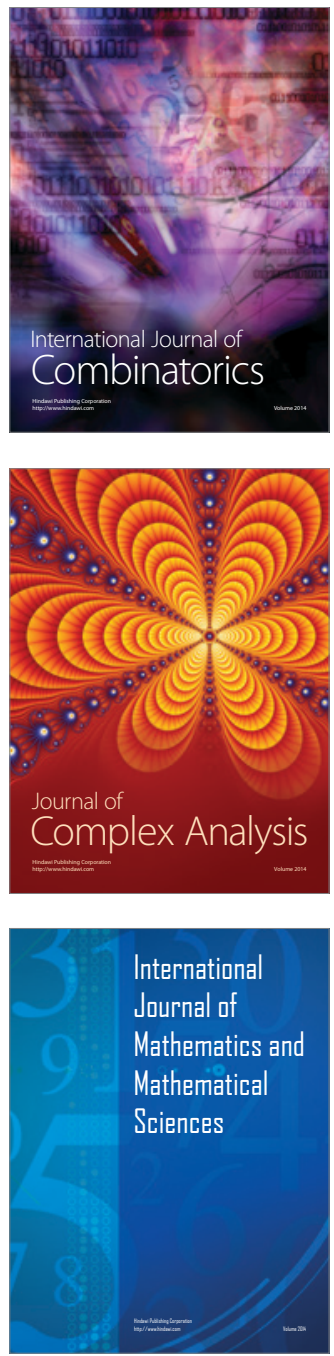
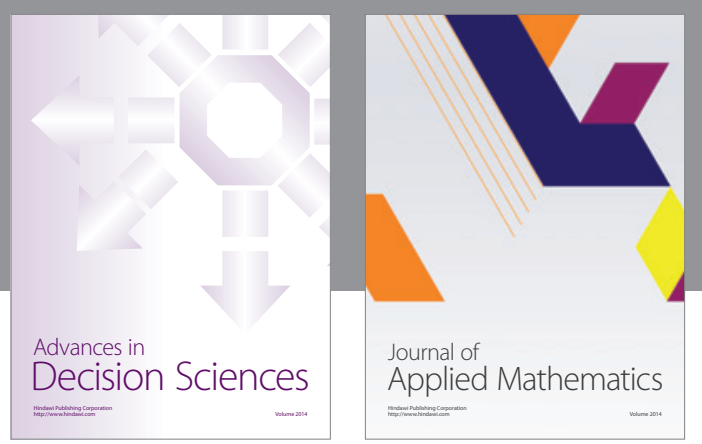

Algebra

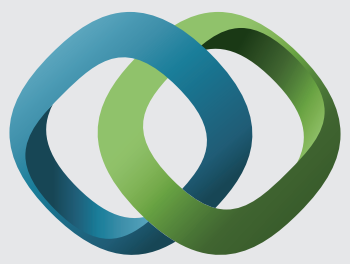

\section{Hindawi}

Submit your manuscripts at

http://www.hindawi.com
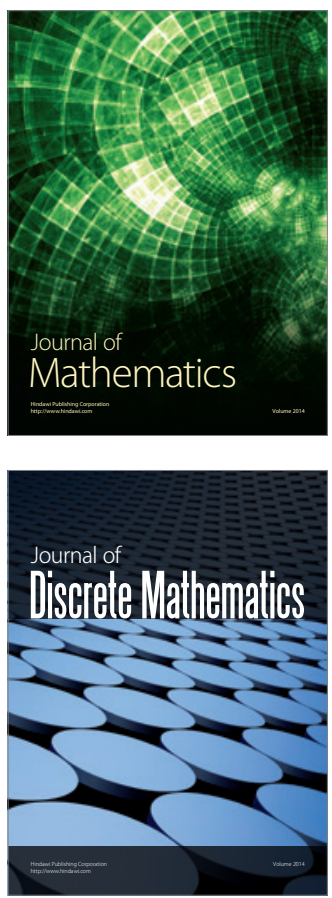

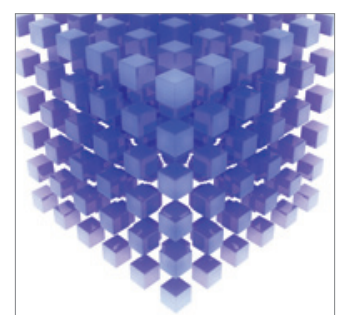

Mathematical Problems in Engineering
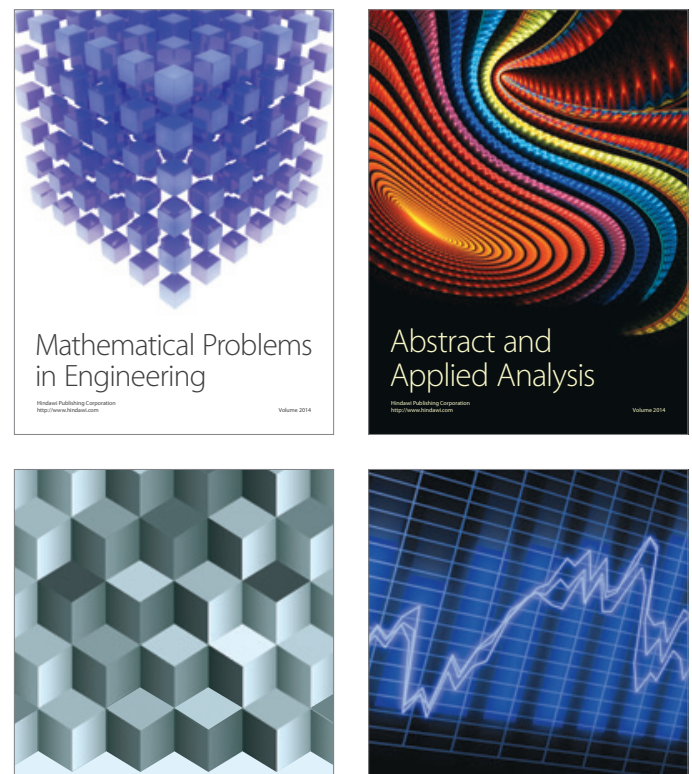

Journal of

Function Spaces

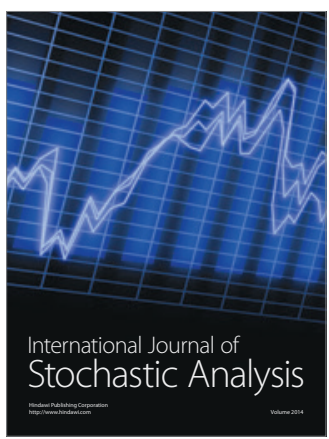

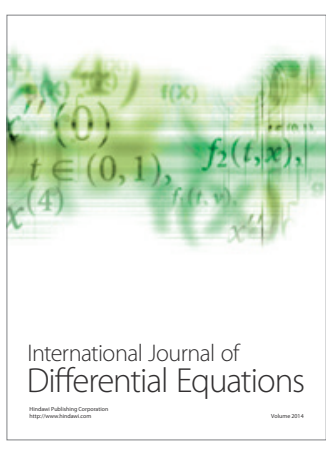
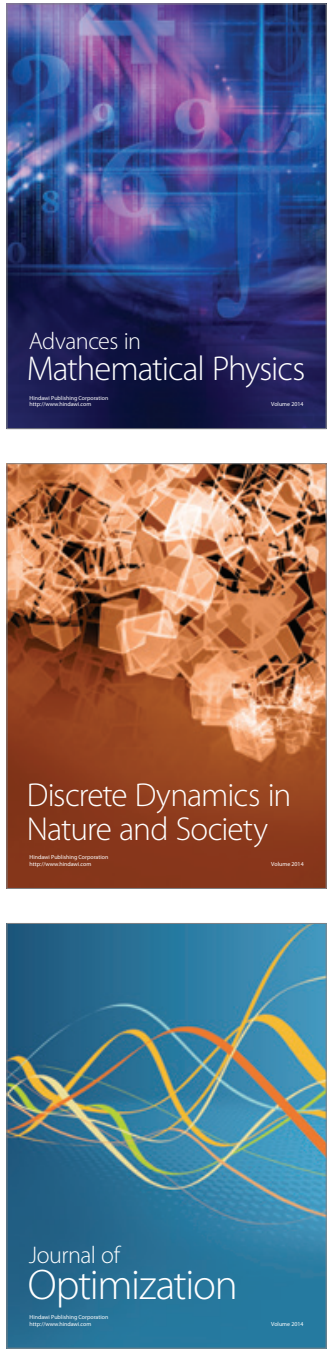